\title{
Crystal Structure of the Monoprotonated Tripodal Ligand Tris(2,2'- bipyrid-6-yl) Methanol
}

\author{
Cuhananthan W. Sathiyajith", James C. Knight, Benson M. Kariuki, Peter G. Edwards and \\ Angelo J. Amoroso*
}

School of Chemistry, Cardiff University, Main Building, Park Place, Cardiff, CF10 3AT, UK

\begin{abstract}
The tripodal bipyridine-based ligand tris(2,2'-bipyrid-6-yl) methanol $\left(\mathrm{L}^{1}\right)$ was shown in our previous work to have a strong steric preference for trigonal prismatic co-ordination environments with a series of transition metals. We now report the crystal structure of the ligand framework, isolated in its monoprotonated form with a perchlorate counterion. The structure was solved in a monoclinic space group $\mathrm{C} 2 / \mathrm{c}$ with cell parameters, $\mathrm{a}=21.5885(3), \mathrm{b}=$ $11.7485(3), \mathrm{c}=24.6939(6) \AA, \alpha=90^{\circ}, \beta=110.790(1)^{\circ}, \gamma=90^{\circ}$, volume $=5855.4(2) \AA^{3}, \mathrm{Z}=8$. The ${ }^{1} \mathrm{H}$ NMR of the protonated ligand is similar to the parent ligand and showed the compound retained its 3 -fold symmetry and all bipyridine groups were equivalent.
\end{abstract}

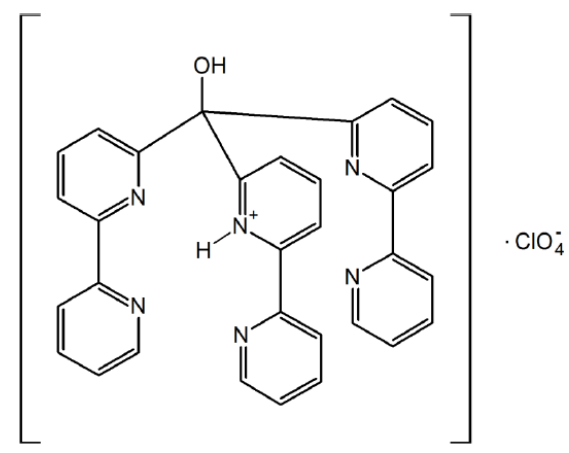

We report the crystal structure of the protonated form a tripodal bipyridine-based ligand framework with a strong steric preference for trigonal pris matic co-ordination environments.

Keywords: Bipyridine, crystal structure, trigonal prismatic, tripodal ligand.

\section{INTRODUCTION}

Self assembly is common place in nature [1] and coordination chemists have provided a new dimension to this natural phenomenon through the driven self assembly of various metal ions with multidentate ligands. For six co-ordinate complexes, the octahedral geometry is overwhelming more common than the trigonal prismatic arrangement. However such arrangements have received intermittent interest in comparison to their octahedral counterparts and recently, they have been investigated for their usefulness to generate molecular assemblies ranging from the macroscale [2] to nano scale [3].

In order to rationalize why specific six-coordinate complexes are biased towards trigonal prismatic character, we generally consider repulsive ligand-ligand interactions, sterochemical predispositions of a ligand as well as the stereo-electronic preferences of metal ions [4].

*Address correspondence to this author at the School of Chemistry Cardiff University Main Building, Park Place, Cardiff CF10 3AT UK; Tel: +44 (0)29 208 74077; Fax: +44 (0)29 208 74030;

E-mails: AmorosoAJ@cardiff.ac.uk and sjithcw@gmail.com
Pioneering work of L. Pauling and R. G. Dickinson's on the study of mineral molybdenite [5], in which sulfur atoms surrounds the molybdenum in a trigonal prismatic coordination arrangement, initially invoked interest in the subject. Consequently, a range of analogous compounds were investigated and shown to exhibit TP or pseudo TP arrangements $[6,7]$. Several other structurally rigid and non rigid ligand systems were also reported. The structurally rigid systems utilised a variety of ligands, such as the bimacrocyclic ligands, bicapped-TRENCAM (BCT) and bicappedTPTCAM (BCTPT) [8], $N, N, N^{\prime}, N^{\prime}$-tetramethylethylenediamine (tmeda) [9], (py) $)_{3}$ tach, (py) ${ }_{3}$ tame and clathrochelates [10], to name but a few. More recently, tris(pyrazolyl)borate $\left(\mathrm{Tp}^{\mathrm{py}}\right)$ based ligand systems were coordinated with Co (II) by Ward and McCleverty et al. [11], and the trigonal prismatic conformation was observed, however other metal ions yielded tetrameric complexes containing octahedrally co-ordinated metals.

Recently, we have investigated the metal driven self assembly of a six-coordinate tripodal ligand, tris(2,2'-bipyrid6 -yl)methanol with series of transition metals [12]. Furthermore, we have focussed our attention in investigating the 
relationship between octahedral and trigonal prismatic character while varying $d$ electron configuration. It was established that unlike the monoanionic $\mathrm{Tp}^{\mathrm{Py}}$, the bipy based ligand naturally favours monomeric complexes as the formation of tetrameric complexes will induce unfavourable electrostatic repulsion. It was concluded that configurationally restrained ligand framework was responsible for enforcing this comparatively rare geometry with respect to an octahedron. In this work we wished to investigate the solid state and solution state structure of the ligand without a metal ion co-ordinated to it. Single crystals of this ligand have been isolated for the first time in the protonated form as a perchlorate salt. We have determined the structure of this species, as well as obtaining the ${ }^{1} \mathrm{H}$ NMR spectra of the ligand and its protonated form. These finding will be discussed below.

\section{EXPERIMENTAL SECTION}

All materials were of reagent grade and used as received from commercial sources. Solvents were distilled before use. Ligand $\mathrm{L}^{1}$ (Fig. 1) was prepared as described in our previous work [12]. L ${ }^{1}$ (50 $\left.\mathrm{mg}, 0.10 \mathrm{mmol}\right)$ was dissolved in methanol (15 mL) and then added dropwise to an aqueous solution of praseodymium(III) perchlorate (110 $\mathrm{mg}, 101 \mathrm{mmol} ; 40 \mathrm{wt} \%$ aqueous solution). The solution was stirred for 20 minutes and left at $4^{\circ} \mathrm{C}$ for 2 days. A light brown precipitate was filtered off and the remaining filtrate was left to slowly evaporate at room temperature, yielding rectangular shaped crystals suitable for X-ray diffraction $(30 \%) .{ }^{1} \mathrm{H}$ NMR $\left(400 \mathrm{MHz} ; \mathrm{CD}_{3} \mathrm{CN}\right): 8.63(d, 3 \mathrm{H}$, $J=8.64 \mathrm{~Hz}$, py-H8), $8.40\left(d, 3 \mathrm{H}, J=8.53 \mathrm{~Hz}, \mathrm{py}-\mathrm{H}_{4}\right), 8.35$ $\left(d, 3 \mathrm{H}, J=8.5 \mathrm{~Hz}, \mathrm{py}-\mathrm{H}_{5}\right), 8.13(t, 3 \mathrm{H}, J=8.38 \mathrm{~Hz}$, py- $\left.\mathrm{H}_{3}\right), 8.05\left(d, 3 \mathrm{H}, J=8.35 \mathrm{~Hz}, \mathrm{py}-\mathrm{H}_{2}\right), 8.00(t, 3 \mathrm{H}$, $J=8.32 \mathrm{~Hz}$, py-H 6 ), 7.55 ( t, $3 \mathrm{H}, J=8.09 \mathrm{~Hz}, \mathrm{py}-\mathrm{H}_{7}$ ).

\section{X-RAY CRYSTALLOGRAPHY}

All single crystal X-ray data was collected at 150 $\mathrm{K}$ on a Bruker/Nonius Kappa CCD diffractometer using graphite monochromatic Mo-K $\alpha$ radiation $(\lambda=0.71073 \AA)$, equipped with an Oxford Cryostream cooling apparatus. Crystal parameters and details of the data collection, solution and refinement are presented in Table 1. The data was corrected for Lorentz and polarisation effects and for absorption using SORTAV [13]. Structure solution was achieved by direct methods (Sir- 92 program system [14] and refined by full-matrix least-squares on $\mathrm{F}^{2}$ (SHELXL-97 [15] with all non-hydrogen atoms assigned anisotropic displacement parameters. Hydrogen atoms attached to carbon atoms were placed in idealised positions and allowed to ride on the relevant carbon atom. In the final cycles of refinement, a weighting scheme that gave a relatively flat analysis of variance was introduced and refinement continued until convergence was reached. Molecular structures in the figures were drawn with ORTEP 3.0 for Windows (version 1.08) [16]. Crystallographic data for 1 in CIF format have been deposited with the Cambridge Crystallographic Data Centre (CCDC 783585). Copies of these later data may be obtained free of charge via www.ccdc.cam.ac.uk/data_request/Cif, by emailing data_request@ccdc.cam.ac.uk, or by contacting the CCDC, 12 Union Road, Cambridge CB2 IEZ, UK; Fax: +44-1223336033.

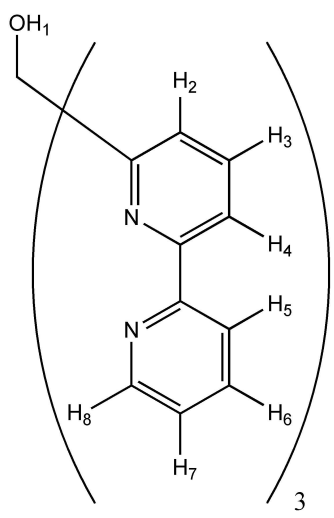

Fig. (1). Ligand $\mathrm{L}^{1}$ showing the proton numbering.

Table 1. Crystal data and structure refinement for 1 .

\begin{tabular}{|c|c|}
\hline Empirical formula & C 31 H29 Cl N6 O8 \\
\hline Formula weight & 649.05 \\
\hline Temperature & $150(2) \mathrm{K}$ \\
\hline Wavelength & $0.71073 \AA$ \\
\hline Crystal system & Monoclinic \\
\hline Space group & $\mathrm{C} 2 / \mathrm{c}$ \\
\hline \multirow[t]{3}{*}{ Unit cell dimensions } & $a=21.5885(3) \AA, \alpha=90^{\circ}$ \\
\hline & $\mathrm{b}=11.7485(3) \AA, \beta=110.790(1)^{\circ}$ \\
\hline & $\mathrm{c}=24.6939(6) \AA, \gamma=90^{\circ}$ \\
\hline Volume & $5855.4(2) \AA^{3}$ \\
\hline $\mathrm{Z}$ & 8 \\
\hline Density (calculated) & $1.473 \mathrm{Mg} / \mathrm{m}^{3}$ \\
\hline Absorption coefficient & $0.195 \mathrm{~mm}-1$ \\
\hline $\mathrm{F}(000)$ & 2704 \\
\hline Crystal size & $0.20 \times 0.20 \times 0.20 \mathrm{~mm}^{3}$ \\
\hline Theta range for data collection & 2.90 to $27.47^{\circ}$ \\
\hline Index ranges & $\begin{array}{c}-27<=\mathrm{h}<=28,-14<=\mathrm{k}<=15,- \\
32<=\mathrm{k}<=31\end{array}$ \\
\hline Reflections collected & 12065 \\
\hline Independent reflections & $6670\left[R_{(\mathrm{int})}=0.0444\right]$ \\
\hline Completeness to $\theta=27.47^{\circ}$ & $99.60 \%$ \\
\hline Absorption correction & Empirical \\
\hline Max. and min. transmission & 0.9620 and 0.9620 \\
\hline Refinement method & Full-matrix least-squares on F2 \\
\hline Data / restraints / parameters & $6670 / 9 / 441$ \\
\hline Goodness-of-fit on $\mathrm{F}^{2}$ & 1.035 \\
\hline Final $\mathrm{R}$ indices $[I \geq 2 \sigma(I)]$ & $R_{1}=0.0514, w R_{2}=0.1087$ \\
\hline $\mathrm{R}$ indices (all data) & $R_{1}=0.0822, w R_{2}=0.1231$ \\
\hline Extinction coefficient & $0.0067(3)$ \\
\hline Largest diff. peak and hole & 0.245 and -0.454 e. $\AA^{-3}$ \\
\hline
\end{tabular}




\section{RESULTS AND DISCUSSION}

The crystal structure of $\mathbf{1}$ is depicted in Fig. (2). The ligand consists of three bipy groups linked via a methine bridge. One of these bipy groups is monoprotonated and is held in a cisoid configuration by an intramolecular hydrogen bond (Table 2). The dihedral angle between the leastsquares planes of these two pyridyl units is just $9.27^{\circ}$. The two remaining bipy groups are not configurationally restrained by any such intramolecular interactions and each exhibits a transoid configuration around the interannular bond. Accordingly, the dihedral angle for the N3/N4containing bipy group is $22.27^{\circ}$ and for the N5/N6containing bipy group this value is larger at $36.54^{\circ}$. The three bipy arms adopt an oblique configuration (Fig. 3), spreading further apart as the sterical influence conferred from the methine bridge is reduced. The $\mathrm{C}-\mathrm{N}$ and mean $\mathrm{C}-\mathrm{C}$ bond lengths for the protonated pyridine are 1.355(3) $\AA$ and 1.384(3) \& respectively. The corresponding values for the neutral pyridyl units are statistically identical at 1.344(3) $\AA$ and 1.385(3) $\AA$. These bond lengths are in excellent agreement with literature values for both 2,2'-bipyridine [17] and 2,2'-bipyridinium (bis)perchlorate [18].

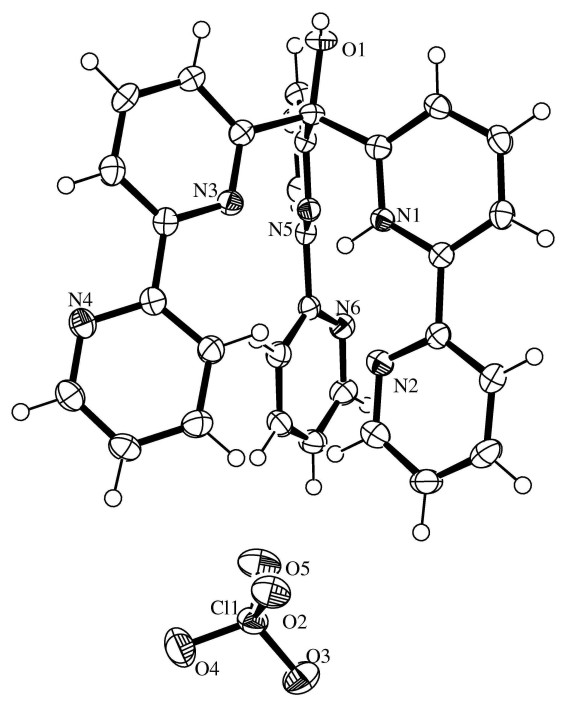

Fig. (2). Perspective view of the asymmetric unit. Displacement ellipsoids are shown at the $50 \%$ probability level. H atoms are represented by circles of arbitrary size. Three water molecules within the lattice have been excluded for clarity.

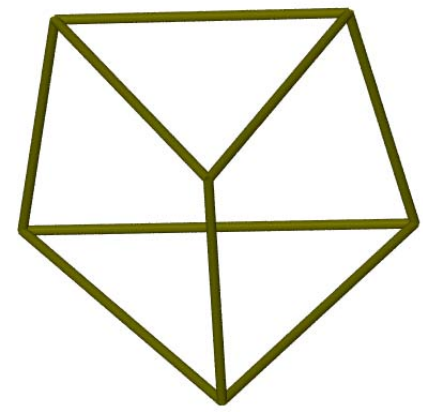

Fig. (3). Highlighting the distorted trigonal prism formed between pyridyl centroids in which the upper triangular face in close proximity to the methine bridge is significantly smaller than the lower triangle formed by the more distant centroids.
Another feature of interest is the orientation of the pyridine rings directly bonded to the bridgehead carbon of the tripod (the proximal pyridine donors). The crystallographic data for tris(2-pyridyl)methanol [19] shows these rings positioned such that all three lone pairs on the nitrogens are pointing away from each other.

However, when protonated, two rings interact with the proton, leading to a N-N distance of $2.656 \AA$ [20]. In contrast, protonated tris(2,2'-bipyrid-6-yl) methanol has all three lone pairs of the proximal pyridine donors pointing towards the proton. In addition, one distal pyridine is also hydrogen bonding to the proton. This distal pyridine (N2$\mathrm{C} 7 / \mathrm{C} 11)$ is part of the bipyridyl unit to which the proton is most strongly associated. The N-N distances between the pyridinium moiety $(\mathrm{N} 1-\mathrm{C} 2 / \mathrm{C} 6)$ and the two other proximal pyridines is 2.786(3) $\AA$ (N1-N5) and 2.852(3) $\AA$ (N1-N3), while the remaining $\mathrm{N}-\mathrm{N}$ distance between these proximal donors is 3.048(3) $\AA(\mathrm{N} 3-\mathrm{N} 5)$. The N-N distance between the proximal pyridinium unit and its distal pyridine is 2.667(3) Å (N1-N2).

The molecular packing is consolidated by various intermolecular interactions, such as $\pi$-stacking between N1$\mathrm{C} 2 / \mathrm{C} 6$ and N2-C7/C11 (symmetry code: 2-x, 1-y, -z; Fig. 4) and several H-bonds involving the perchlorate counterion and three water molecules. The alcohol group (O1) is also acting as an H-bond donor to a water molecule (O8) within the lattice.

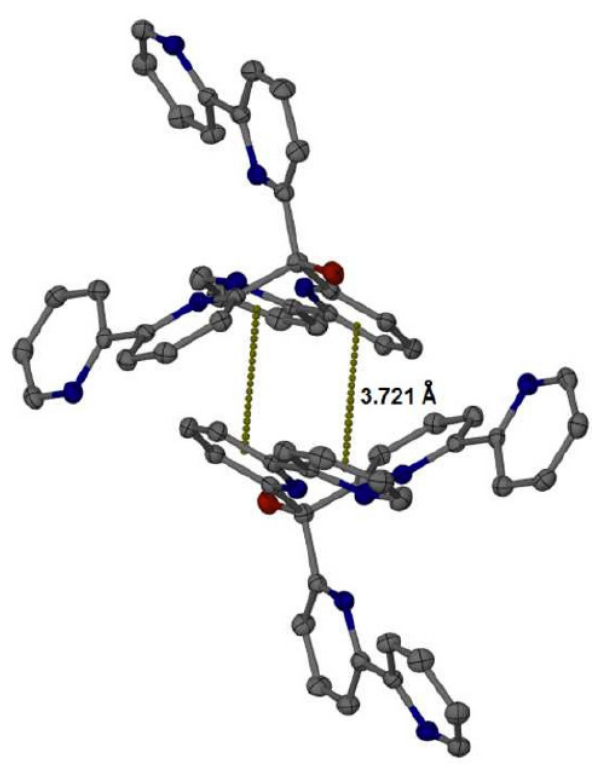

Fig. (4). Fragment of the title structure, viewed along the c-axis showing the $\pi$-stacking interactions (gold dotted lines) between symmetrically related molecules (symmetry code: 2-x, 1-y, -z) which support the molecular packing. Hydrogen atoms have been excluded for clarity.

The ${ }^{1} \mathrm{H}$ NMR 2-D COSY spectra of both the monoprotonated and neutral forms of $\mathbf{1}$ were measured in order to elucidate the coupling behaviour within the aromatic region and thus unambiguously assign the resonances (Fig. $\mathbf{5}$ and Fig. 6, respectively). First, one can note that the addition of a single proton to the tripod structure does not destroy the $\mathrm{C}_{3}$ symmetry of the molecule and all bipyridyl moieties are still 
Table 2. H-bonding geometry $\left(\AA,^{\circ}\right)$ for 1 .

\begin{tabular}{|c|c|c|c|c|}
\hline Intra N(1)---H(1)....N(2) & 0.88 & 2.29 & $2.667(3)$ & 106 \\
\hline Intra N(1)---H(1)...N(5) & 0.88 & 2.36 & $2.786(3)$ & 110 \\
\hline $\mathrm{O}(1)---\mathrm{H}(1 \mathrm{~A}) \ldots \mathrm{O}(8)^{i}$ & 0.84 & 1.83 & $2.649(3)$ & 164 \\
\hline $\mathrm{O}(6)---\mathrm{H}(6 \mathrm{~B}) \ldots . \mathrm{O}(3)$ & $0.90(6)$ & $2.23(6)$ & $3.116(4)$ & $166(5)$ \\
\hline $\mathrm{O}(7)---\mathrm{H}(7 \mathrm{~A}) \ldots . \mathrm{N}(4)^{i i}$ & $0.90(5)$ & $2.03(5)$ & $2.917(3)$ & $165(4)$ \\
\hline $\mathrm{O}(7)---\mathrm{H}(7 \mathrm{~B}) \ldots \mathrm{N}(6)^{i i i}$ & $0.89(4)$ & $2.07(4)$ & $2.953(3)$ & $170(4)$ \\
\hline
\end{tabular}

Symmetry codes: $i=1 / 2+\mathrm{x}, 1 / 2-\mathrm{y}, 1 / 2+\mathrm{z}, i i=\mathrm{x},-\mathrm{y}, \mathrm{z}-1 / 2, i i i=\mathrm{x}, 1-\mathrm{y}, \mathrm{z}-1 / 2, i v=3 / 2-\mathrm{x}, 1 / 2+\mathrm{y},-\mathrm{z}-1 / 2$

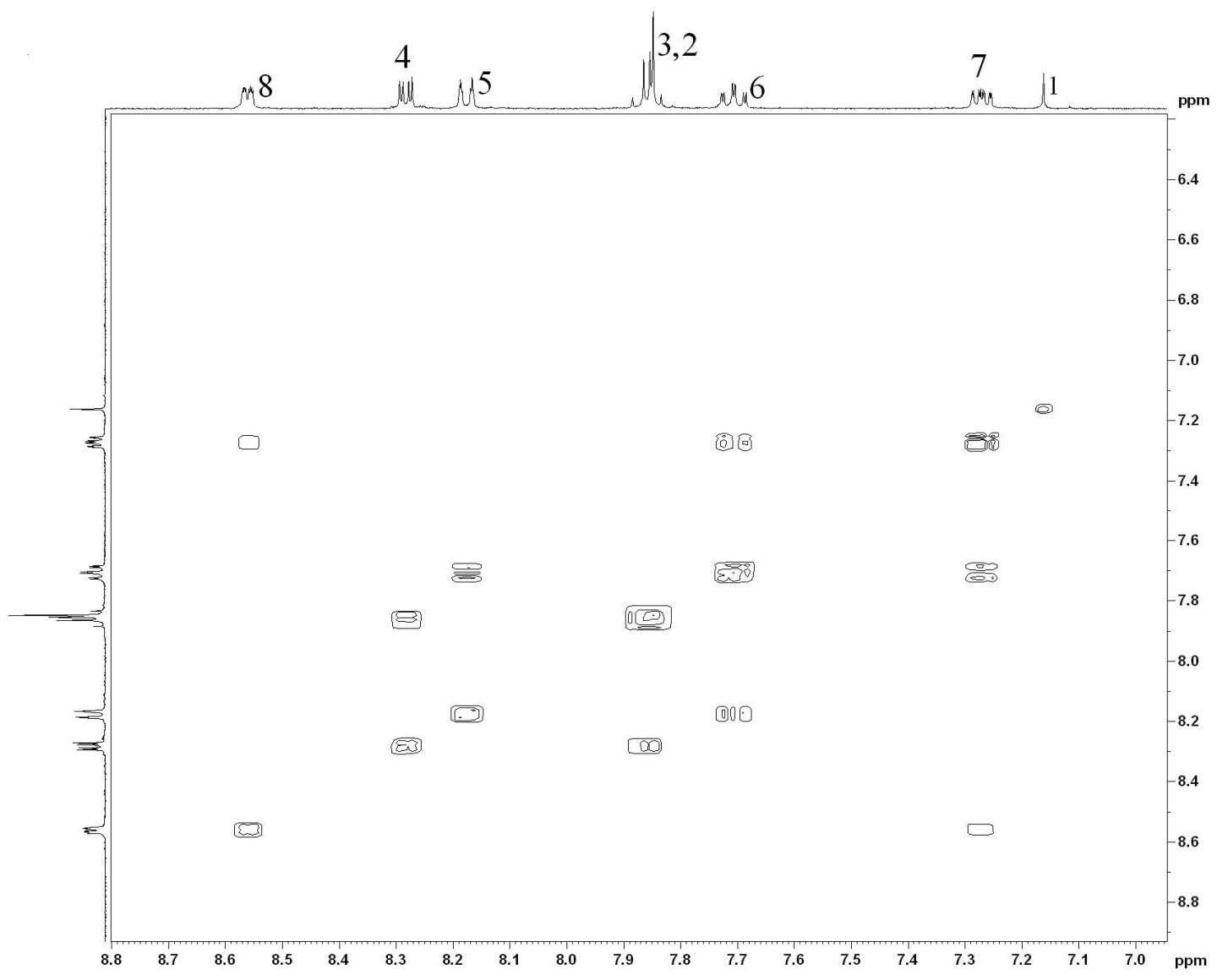

Fig. (5). A COSY map showing the expanded aromatic region of the neutral unprotonated ligand taken at $293 \mathrm{~K}$ in $\mathrm{CD} 3 \mathrm{CN}$.

equivalent. This would be consistent with fluxional behaviour of the proton, faster than the NMR timescale. Also, whilst the proton resonance frequencies for both the monoprotonated and neutral ligand exhibit similar ordering, those of the protonated form are shifted slightly downfield as one would expect from the deshielding effect of adding a proton to the pyridine ring [21].
In both cases, there exists strong coupling between vicinal protons around each of the pyridine groups. This allow us to unambiguously group the resonances for each pyridyl ring $\left(\left(\mathrm{H}_{2}, \mathrm{H}_{3}, \mathrm{H}_{4}\right)\right.$ vs $\left.\left(\mathrm{H}_{5}, \mathrm{H}_{6}, \mathrm{H}_{7}, \mathrm{H}_{8}\right)\right)$, when considering the cross peaks. By then assigning the peak which the highest ppm to $\mathrm{H}_{8}$ (ortho to the nitrogen atom), this allows the full assignment of all peaks. This is particularly useful in 


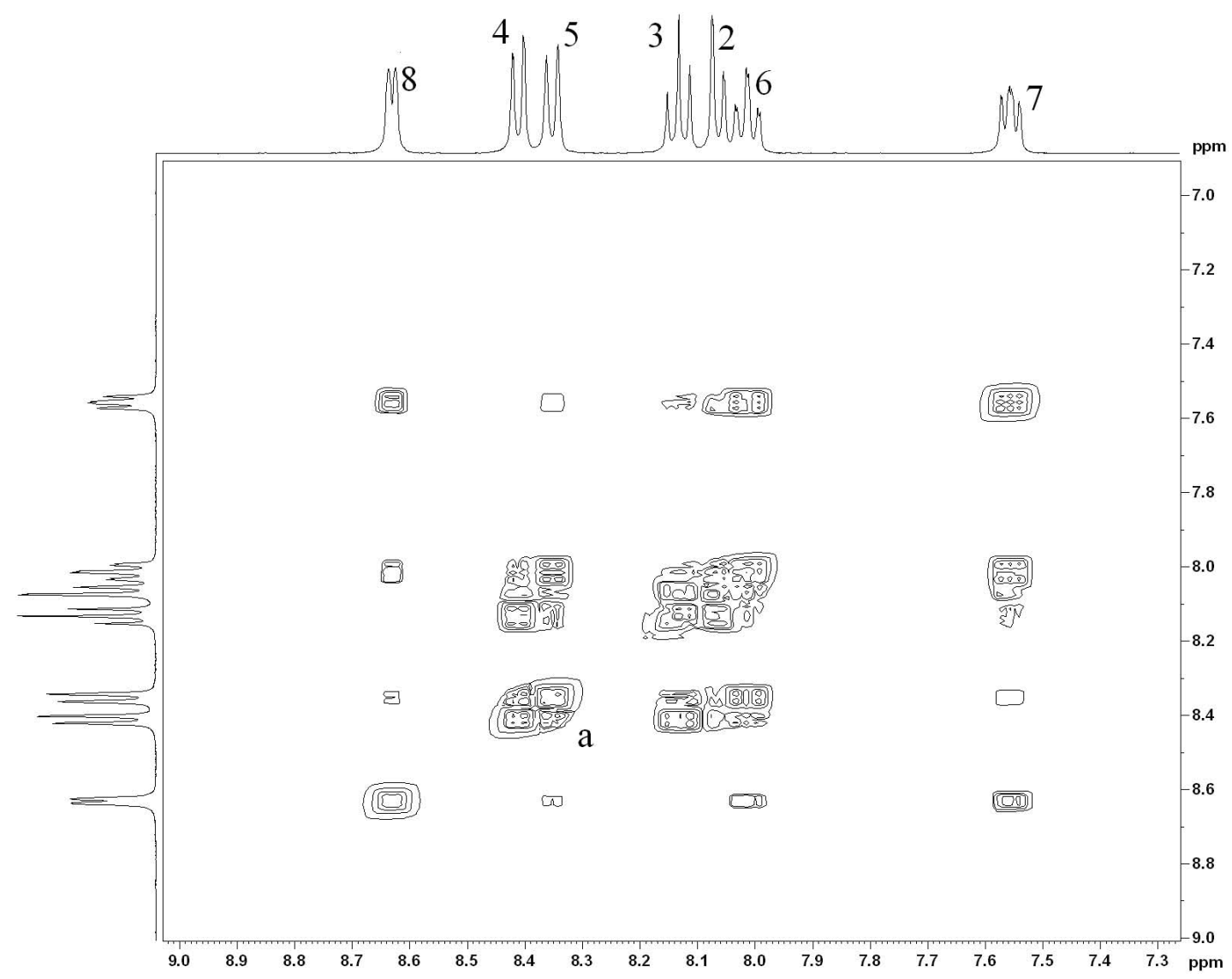

Fig. (6). A COSY map showing the expanded aromatic region of the protonated ligand taken at $293 \mathrm{~K}$ in $\mathrm{CD}_{3} \mathrm{CN}$.

discriminating between $\mathrm{H}_{4}$ and $\mathrm{H}_{5}$ as well as $\mathrm{H}_{3}$ and $\mathrm{H}_{6}$. This allows us to determine that the relative ordering of all resonances is unchanged between the protonated and free ligand and suggests there is no preferencial localisation of the proton on one of the two different pyridyl rings.

The protonated ligand also reveals evidence of long range coupling between the two pyridines, which are in a cisoid arrangement, specifically through $\mathrm{H}_{4}$ and $\mathrm{H}_{5}$ (labelled a).

\section{CONCLUSION}

In conclusion, we have shown that the solid state structure of the protonated form of the ligand $\mathrm{L}^{1}$ has a structure consisting of the three bipyridyl moieties connected to a central carbon. The pyridyl rings connected directly to the central carbon all having their nitrogen donor pointing to the centre of the molecule, perhaps suggesting they all interact with the proton. The other three nitrogen donors on the outermost pyridines vary in their behaviour, with two having a transoid arrangement within the bipyridine moieties and one being cis. However, this asymmetric arrangement is not observed in the solution state as ${ }^{1} \mathrm{H}$ NMR identifies $\mathrm{C}_{3}$ symmetry in the complex. COSY NMR has allowed us to unambiguously assign the proton resonances. Interestingly, the similar ordering of the resonances, in the free ligand compared to its protonated form, suggests little difference in the relative electron density within a compound.

\section{CONFLICT OF INTEREST}

The authors confirm that this article content has no conflict of interest.

\section{ACKNOWLEDGEMENTS}

We gratefully acknowledge the support of Cardiff University.

\section{REFERENCES}

[1] Whitesides, G.M.; Boncheva, M. Beyond molecules: Self-assembly of mesoscopic and macroscopic components. Proc. Natl. Acad. Sci. US A., 2002, 99, 4769-4774

[2] Hu, W.J.; Liu, L.Q.; Ma, M.L.; Zhao, X.L.; Liu, Y.A.; Mi, X.Q.; Jiang, B.; Wen, K. A Trigonal Prismatic Ligand in the MetalMediated Self-Assembly of One- and Two-Dimensional Metallosupramolecular Polymers. Inorg. Chem., 2013, 52, 9309-9319.

[3] Company, A.; Roques, N.; Güell, M.; Mugnaini, V.; Gómez, L.; Imaz, I.; Datcu, A.; Solà, M.; Luis, J.M.; Veciana, J.; Ribas, X.; Costas, M. Nanosized trigonal prismatic and antiprismatic CuII coordination cages based on tricarboxylate linkers. Dalton. Trans., 2008, 37(13), 1679-1682;

[4] Gillum, W.O.; Huffman, J.C.; Streib, W.E.; Wentworth, R.A.D Trigonal Prismatic Co-ordination in the cis,cis-1,3,5-Tris(pyridine2 carboxaldimino)cyclohexanezinc(II) Ion. J. Chem. Soc., 1969, (15), 843-844.

[5] Dickinson, R.G.; Pauling, L. The crystal structure of molybdenite J. Am. Chem. Soc., 1923, 45, 1466-1471.

[6] (a) Eisenberg, R.; Ibers, J.A. Trigonal Prismatic Coordination. The Molecular Structure of Tris(cis-1,2-diphenylethene-1,2dithiolato)rhenium. J. Am. Chem. Soc., 1965, 87, 3776-3778. (b) Eisenberg, R.; Ibers, J.A. Trigonal Prismatic Coordination. The 
Crystal and Molecular Structure of Tris(cis-1,2-diphenylethene1,2-dithiolato)rhenium. Inorg. Chem., 1966, 5, 411-416.

[7] (a) Eisenberg, R.; Stiefel, E.I.; Rosenberg, R.C. Six-Coordinate Trigonal-Prismatic Complexes of First-Row Transition Metals. $J$. Am. Chem. Soc., 1966, 88, 2874-2876. (b) Eisenberg, R.; Gray, H.B. Trigonal-prismatic coordination. Crystal and Molecular Structure of Tris (cis-1,2-diphenylethylene-1,2-dithiolato)vanadium. Inorg. Chem., 1967, 6, 1844-1849.

[8] Karpishin, T.B.; Stack, T.D.P.; Raymond, K.N. Octahedral versus trigonal prismatic geometry in a series of catechol macrobicyclic ligand-metal complexes. J. Am. Chem. Soc., 1993, 115, 182-192.

[9] Morse, P.M.; Girolami, G.S. Are d $\mathrm{d}^{0} \mathrm{ML}_{6}$ complexes always octahedral? The $x$-ray structure of trigonal-prismatic [Li(tmed) $]_{2}\left[\mathrm{ZrMe}_{6}\right]$. J. Am. Chem. Soc., 1989, 111, 4114-4116.

[10] (a) Parks, J.E.; Wagner, B.E.; Holm, R.H. Three-dimensional macrocyclic encapsulation reactions. I. Synthesis of six-coordinate complexes with nonoctahedral stereochemistry. J. Am. Chem. Soc., 1970, 92, 3500-3502. (b) Parks, J.E.; Wagner, B.E.; Holm, R.H. Three-dimensional macrocyclic encapsulation reactions. II. Synthesis and properties of nonoctahedral clathro chelates derived from tris(2-aldoximo-6-pyridyl)phosphine and boron trifluoride or tetrafluoroborate. Inorg. Chem., 1971, 10, 2472-2478. (c) Churchill, M.R.; Reis, A.H. Structural studies on clathro chelate complexes. I. Trigonal-prismatic coordination of $\mathrm{d} 8$ nickel(II) in crystalline [fluoroborotris(2-aldoximo-6-pyridyl)phosphine]nickel(II) tetrafluoroborate. Inorg. Chem., 1972, 11, 1811-1818.

[11] Paul, R.L.; Amoroso, A.J.; Jones, P.L.; Couchman, S.M.; Reeves, Z.R.; Rees, L.H.; Jeffery, J.C.; McCleverty, J.A.; Ward, M.D. Effects of metal co-ordination geometry on self-assembly: a monomeric complex with trigonal prismatic metal co-ordination vs. tetrameric complexes with octahedral metal co-ordination. $J$. Chem. Soc., 1999, 28(10), 1563-1568.

[12] Knight, J.C.; Alvarez, S.; Amoroso, A.J.; Edwards, P.G.; Singh, N. A novel bipyridine-based hexadentate tripodal framework with a strong preference for trigonal prismatic co-ordination geometries. Dalton. Trans., 2010, 39(16), 3870-3883.

[13] Blessing, R.H. An empirical correction for absorption anisotropy. Acta. Crystallogr. A, 1995, 51, 33-38.

[14] Altomare, A.; Cascarano, G.; Giacovazzo, C.; Guagliardi, A. Completion and refinement of crystal structures with SIR92. J. Appl. Crystallogr., 1993, 26, 343-350.

[15] Sheldrick, G.M. SHELXL-97: Program for the Refinement of Crystal Structures. University of Göttingen: Göttingen, Germany, 1997.

[16] Farrugia, L.J. Ortep-3 for Windows - A Version of ORTEP-III with a Graphical User Interface (GUI). J. Appl. Crystallogr., 1997, 30, 565 .

[17] Merritt, Jr.L.L.; Schroeder, E.D. The Crystal Structure of 2,2'Bipyridine. Acta. Crystallogr., 1956, 9, 801-804.

[18] Ma, G.; Ilyukhin, A.; Glaser, J. 2,2'-Bipyridinium bis(perchlorate). Acta. Crystallogr. C., 2000, 56, 1473-1475.

[19] Keene, F.R.; Snow, M.R.; Tiekink, E.R.T. Tris(2-pyridyl)methanol. Acta. Crystallogr. C., 1988; 44, 937-938.

[20] Boggess, R.K. Monoprotonated perchlorate salt of tris(2pyridyl)methanol. Acta. Crystallogr. C., 1992, 48, 1327-1329.

[21] Proton NMR data for the neutral ligand $\left(400 \mathrm{MHz} ; \mathrm{CDCl}_{3}\right): \delta 8.55$ $(\mathrm{d}, 3 \mathrm{H}, J=7.8 \mathrm{~Hz}), 8.28(\mathrm{~d}, 3 \mathrm{H}, J=7.5 \mathrm{~Hz}), 8.12(\mathrm{~d}, 3 \mathrm{H}, J=7.2$ $\mathrm{Hz}), 7.89-7.72(\mathrm{~m}, 6 \mathrm{H}), 7.67(\mathrm{t}, 3 \mathrm{H}, J=7.5 \mathrm{~Hz}), 7.21(\mathrm{t}, 3 \mathrm{H}, J=$ $7.2 \mathrm{~Hz}), 5.21(\mathrm{~s}, 1 \mathrm{H})$

(c) Sathiyajith et al.; Licensee Bentham Open.

This is an open access article licensed under the terms of the Creative Commons Attribution Non-Commercial License (http://creativecommons.org/licenses/by-nc/3.0/) which permits unrestricted, non-commercial use, distribution and reproduction in any medium, provided the work is properly cited. 